Año 9. Núm. 24

Recibido el 12 de junio de 2016.

Dictamen favorable el 17 diciembre de 2016.

\title{
Mecanismos Alternativos de Solución en el Sistema \\ Acusatorio Oral.
}

Carlos Alfredo González Galaviz

\section{Resumen}

Con la nueva implementación del sistema penal acusatorio oral que fue publicada el 18 de junio del 2008 y la reforma al artículo 17 de la constitución, que menciona "las leyes preverán mecanismos alternativos de solución de controversias". Este nuevo proceso de Mecanismos Alternativos tiene como finalidad proporcionar, a través de diálogo, la solución de una controversia para que no se llegue al juicio, y que ambas partes de manera voluntaria puedan encontrar una solución factible para la situación. Esta investigación dará a conocer al lector sobre los beneficios y las ventajas de la nueva implementación del sistema acusatorio oral. Si bien se sabe que los juicios pueden llegar a ser demasiado duraderos y en muchos casos las partes no quedan satisfechas con la resolución dictada por el juez. Los Mecanismos Alternativos son una manera más rápida de solucionar una controversia y las partes llegan a un acuerdo mutuo para solucionar su conflicto. El objetivo de este trabajo es dar a conocer al público en general, sobre el juicio oral, los Mecanismos Alternativos que nos ofrece y la eficacia que tendrá a corto, mediano y largo plazo en nuestro país, y poder respondernos ¿Fue necesario implementar este nuevo sistema penal acusatorio? ¿Serán efectivos los 
Año 9. Núm. 24 "El saber de mis hijos
hará mi grandeza"

(Edición especial julio- diciembre 2016)

Mecanismos Alternativos de Solución de Controversia?

\section{http://revistainvestigacionacademicasinfrontera.com}

Revista de Investigación

Académica sin Frontera ISSN: 2007-8870

\section{Introducción}

Previa la inclusión de la constitución política de los estados unidos mexicanos de la reforma en materia penal publicada en el diario oficial de la federación el 18 e junio de 2008, en la que se implementa el sistema acusatorio en el procedimiento penal de nuestro país, debemos realizar análisis de dicha reforma constitucional y en su caso, estudiar sus implementaciones procesales. Mediante dicha reforma se modificó el artículo 17 constitucional en su 4to párrafo que nos menciona sobre los "Mecanismos Alternativos de Solución de Controversias".

La siguiente investigación busca establecer un análisis coherente respecto de las ventajas que tiene el nuevo sistema acusatorio oral mediante sus mecanismos alternativos, así como explicar el "porque" el poder ejecutivo implemento dicho sistema en nuestro país.

La finalidad es dar a conocer al público en general, sobre la eficacia que conlleva utilizar los mecanismos alternativos y la eficacia que tendrá a corto, mediano y largo plazo en nuestro país, para responder: ¿Serán efectivos los mecanismos alternativos de solución de controversias?

\section{Planteamiento del tema}

Con la nueva implementación del sistema penal acusatorio oral que fue publicada el 18 de junio del 2008 y la reforma al artículo 17 de la Constitución Política de los 


\section{http://revistainvestigacionacademicasinfrontera.com}

Estados Unidos Mexicanos, que menciona que "Las leyes preverán mecanismos alternativos de solución de controversias".

Este nuevo proceso de Mecanismos Alternativos tiene como finalidad proporcionar, a través de diálogo, la solución de una controversia para que no llegue a un juicio, y que ambas partes con un acuerdo mutuo puedan encontrar una solución factible a su situación, siendo más eficaz y eficiente el proceso.

\section{Referencias Teóricas}

\section{Antecedentes}

El origen de los mecanismos alternativos de solución de controversias en el país, empezó en los años noventa del siglo anterior, sus primeras experiencias fueron en las aulas de postgrado en la facultad de Derecho de la Universidad de Sonora campus Hermosillo, al incluir al plan de estudios la materia de Mediación y Psicología aplicada a la práctica judicial.

Posteriormente en el año de 1998 en la ciudad de Hermosillo se creó la Institución de Mediación de México, la permitió coadyuvar en el desarrollo de la mediación y de la justicia restaurativa en la mayoría de los Estados de la Republica, ayudando con su implementación en las sedes tribunalicias.

La constitución política de los estados unidos mexicanos con la reforma y adición de su artículo 17, párrafo cuarto ha incorporado los mecanismos alternativos de solución de controversias al orden jurídico nacional, plasmando en su texto legal el derecho a una justicia alternativa.

El artículo mencionado dispone en su párrafo cuarto que "las leyes preverán 


\section{http://revistainvestigacionacademicasinfrontera.com}

mecanismos alternativos de solución de controversias. En la materia penal regularan su aplicación, aseguraran la reparación del daño y establecerán los casos en los que se requerirá supervisión judicial".

La finalidad de los mecanismos alternativos de solución de controversias, es propiciar, a través del dialogo la solución de las controversias que surgen entre miembros de la sociedad con motivo de la denuncia o querella referidos a un hecho delictivo, mediante procedimientos basado en la oralidad, economía procesal y la confidencialidad.

En la actualidad existen varios tipos de Mecanismos Alternativos como lo son: La Conciliación, la Mediación, entre otras, dependiendo del tipo de conflicto, que son tanto para solucionar la controversia como también para la búsqueda de tranquilidad y armonía de los protagonistas del problema.

\section{Mediación}

Farré salvá define a la mediación como, "un proceso de resolución de conflictos, privado, confidencial y voluntario, que permite que las partes implicadas puedan comunicarse entre sí, expresando, entre otros, sus puntos de vista, argumentos, intereses, necesidades o expectativas y llegando, en su caso, a acuerdos mutuamente consentidos, acompañadas de un tercero imparcial, la persona mediadora, quien actúa como facilitadora del mismo, y que vela por su legítimo funcionamiento, creando así un espacio de diálogo en el que prevalezca la equidad comunicativa, la seguridad, la libertad y la igualdad entre las partes". (Salva, 2010)

Por otra parte en la Ley Nacional de los Mecanismos Alternativos de Solucion de 
Año 9. Núm. 24

Revista de Investigación

Académica sin Frontera ISSN: 2007-8870

\section{http://revistainvestigacionacademicasinfrontera.com}

Controversias nos define a la mediacion como "un mecanismo voluntario mediante el cual los intervinientes, en libre ejercicio de su autonomia, buscan, construyen y proponen opciones de solucion a la controversia, con el fin de alcanzar la solucion de esta. El facilitador durante la mediacion propicia la comunicación y entendimiento mutuo entre los intervinientes.

Al tener las definiciones anteriores podemos darnos cuenta que la mediacion es simplemente una conversacion que tienen las partes sobre lo que les esta afectando el conflicto, es decir, que es lo que sienten con respecto al problema, dicho dialogo es guiado por una tercera persona que se encargara de establecer un orden, para que ninguna de las partes ataque tanto como psicologicamente 0 fisicamente a la otra, manteniendo el respeto entre ambos de manera imparcial y equitativa.

La mediacion busca generar que las partes no se vean como un "tu" o un "yo" si no un "nosotros" al momento de dar soluciones a la controversia para lograr que ambos protagonistas se sientan tranquilos con el acuerdo.

En el proceso de este mecanismo alternativo el facilitador dara una explicacion breve del proposito de la sesion, asi como tambien mencionara las reglas que se estableceran y sera el encargado de formular preguntas para que los intervinientes, es decir las partes puedan plantear sus pretensiones, preocupaciones y asi poder dar una posible solucion a la controversia existente.

\section{Conciliacion}

Soto Lamadrid nos dice que la conciliacion "es una negociación 


\section{http://revistainvestigacionacademicasinfrontera.com}

asistida en la que un tercero guía a las partes en un proceso integrado por etapas y propone fórmulas de solución que serán valoradas por los participantes" (Lamadrid, 2016).

Así mismo, la Ley de Justicia Alternativa del Estado de baja California, define "la conciliación como un procedimiento voluntario por el cual dos o más personas involucradas en una controversia, logran solucionarla, a través de la comunicación dirigida, mediante recomendaciones y sugerencias de solución facilitadas".

Podemos observar que tiene mucha similitud con la mediación excepto que el facilitador en este mecanismo alternativo tiene la facultad de poder proponer a las partes a crear una solución. También debemos mencionar que el proceso de conciliación debe de ser por voluntad de ambas partes, si una de las partes no quiere llevar el proceso no podrá efectuarse. Uno de los beneficios de la conciliación es que dicho tercero podrá opinar sobre el problema, y hacer ver a las partes que es lo que deben hacer.

\section{Junta Restaurativa}

El artículo 27 de la Ley Nacional de Mecanismos Alternativos nos da el concepto que dice "es el mecanismo mediante el cual la victima u ofendido, el imputado y, en su caso, la comunidad afectada, en libre ejercicio de su autonomía, buscan, construyen y proponen opciones de solución a la controversia, con el objeto de lograr un Acuerdo que atienda las necesidades y responsabilidades individuales y colectivas, así como la reintegración de la víctima u ofendido y del imputado a la comunidad y la recomposición del tejido social".

Con la definición anterior nos damos cuenta que la junta restaurativa es un proceso por el cual tanto como la víctima como el imputado tienen que pasar, con 


\section{http://revistainvestigacionacademicasinfrontera.com}

el fin de que puedan eliminar ese daño emocional que puede causar la controversia y llevar una vida normal con la sociedad sin el trauma psicológico causado. En este proceso el facilitador realizara sesiones preparativas para cada uno de los involucrados, les explicara las reglas, sus alcances, metodología e intentara despejar cualquier duda que se plantee.

\section{Negociación}

La Negociación la observamos diariamente en nuestra vida cotidiana, es cuando las partes a través del dialogo llegan a un acuerdo en el que ambos quedan conformes, citando a Juan García Montufar, define a la negociación como "Un medio de solución de conflictos en el que las partes buscan persuadir una a la otra del hecho que su percepción de una situación determinada es la correcta". Con la ayuda de un facilitador que emplee una comunicación de respeto entre ambas partes siendo parcial podría lograrse un resultado más favorable. En este contexto, la negociación debe ser considerada como un mecanismo alternativo de solución de conflicto, y estar contemplada en la Ley Nacional de Mecanismos Alternativos

\section{Metodología}

Con el proceso de Mecanismos Alternativos de solución de Controversias podemos llegar a una resolución más rápida, en el que las partes propongan su propia posible solución, es decir, que ellos sean los que solucionen su conflicto sin necesidad de acudir a las autoridades. En muchos de los casos las personas no quedan conformes con las resoluciones dictadas por los jueces, y siguen emocionalmente dañados (inconformes). 


\section{http://revistainvestigacionacademicasinfrontera.com}

El sistema anterior era muy tedioso, es decir, el juicio se llegaba a prolongar mucho tiempo, por lo tanto mucha de la población al momento de llevar un proceso optan por desistir. Con la nueva ley de Mecanismos Alternos pueden ir a un proceso por el cual llegan a la solución en mucho menor tiempo y con un acuerdo mutuo de ambas partes.

\section{Conclusión}

Partiendo de la investigación que se realizó con el nuevo sistema que ofrece los mecanismos alternativos de solución de controversias, podemos llegar a la conclusión de que llevar un proceso de esa manera es mucho más confortable para las partes, ya que no les tomaría mucho tiempo y llegarían a alcanzar una mayor armonía emocionalmente, para asi poder readaptarse con la sociedad y las personas optarían más por solucionar sus problemas de una manera que ellos mismos puedan dar una posible respuesta a su controversia para poder satisfacer su propio interés.

\section{Fuentes Consultadas}

- Ley Nacional De Mecanismos Alternativos De Solucion De Controversias

- Farré Salvá, Sergi, Gestion de Conflictos: taller de mediacion. Un enfoque socioafectivo, 4ª ed., España, Ariel, 2010, p. 119 
http://revistainvestigacionacademicasinfrontera.com

- Miguel Angel Soto Lamadrid, Jorge Pesqueira leal y otros, Justicia Alternativa y Sistema Acusatorio, 3르 ed., Mexico, 2016, p. 34, 38, 43, 213

- Diccionario Juridico

- Juan Garcia Montufar, Los Medios Alternativos de Solucion de Conflictos, articulo,URL

http://blog.pucp.edu.pe/blog/derysoc/2008/08/18/los-medios-alternativos-desolucion-de-conflictos/ 